\title{
Arquitetura Algorítmica: Processos e Ferramentas
}

\section{Algorithmic Architecture: Processes and Tools}

\author{
Victor Calixto \\ Universidade Presbiteriana Mackenzie, Brasil \\ arq.victorcalixto@gmail.com \\ Charles C. Vincent \\ Universidade Presbiteriana Mackenzie, Brasil \\ charles.vincent@mackenzie.br
}

\begin{abstract}
This paper presents the results of an academic research in the field of parametric-generative design and through projective tests and processes using parametric tools and computational logic. Thus, five experiments for the region of the Terminal Bandeira Flag Square were set forth. From the urban guidelines and an object in common, it was a distinct possibility, where it was possible to analyze the advances and setbacks in the process of project development. The approach taken is an exploration of design processes that involve computational logic for formulating, exploring and creating architectural themes and its interfaces with other fields of knowledge: algorithmic architecture.
\end{abstract}

Keywords: Performance-based design; Parametric modeling; Simulation.

\section{Introducção}

Um algoritmo não é necessariamente um programa de computador, mas sim um procedimento lógico com etapas finitas e bem estabelecidas, para ser executado dentro de um tempo finito. Com o inicio da era da computação algoritmos passam a ser implementados em sua plenitude, com a finalidade de resolver problemas de alta complexidade, até então inimagináveis para o processamento do cérebro humano.

"Algotecture" (1) é o termo criado por Kostas Terzidis para definir o uso de algoritmos na arquitetura. Terzidiz deixa claro que o pensamento algorítmico não está diretamente ligado ao uso do computador, mas que, através do uso do mesmo, podemos expandir nossas limitações humanas trabalhando em uma parceria designer-máquina.

Atualmente são muitas as explorações metodológicas que se valem de algoritmos em arquitetura, mas com uma teoria ainda não claramente sistematizada, por se tratar de um processo que rompe com as assunções tradicionais em projeto, assunções reveladas no binômio design-desígnio que comumente se associa ao ato de projetar.

São três os temas relevantes nesta exploração que envolvem processos algorítmicos com o uso do computador: Morphing, Performance e Generativo. É importante evidenciar que estes não são os únicos processos discutidos atualmente em arquitetura, mas sim um recorte definido para este trabalho e que por muitas vezes estes processos podem se inter-relacionar, tangenciar ou mesclar-se, dificultando a sistematização ou a rotulação dos mesmos.

\section{Ensaios}

O objeto de projeto foi a reestruturação do Terminal das Bandeiras e a criação de um espaço público de interligação entre centro velho e centro novo da cidade de São Paulo. O principal software utilizado para essa pesquisa foi Rhinoceros 3D com o plugin Grasshopper.

São apresentados cinco ensaios projetuais para a região da Praça da Bandeira. Partindo de diretrizes urbanísticas e um objeto em comum, chegou-se a distintas possibilidades, onde foi possível analisar os avanços e retrocessos no processo do desenvolvimento do projeto.

\section{Ensaio 1}

Os primeiros estudos foram fortemente influenciados pelo livro "São Paulo - razões de arquitetura" (2), de Angelo Bucci, que descreve quatro proposições arquitetônicas para se realizar intervenções em São Paulo: mirar, transpor, invadir e infiltrar.

Após reflexão, pequenas subversões surgiram em tais proposições: porque o transpor deve ligar o ponto $A$ ao ponto $B$ diretamente em uma relação puramente funcional? Seria possível pensar essa transposição como uma transposição flâneur, que perambula não pelo caminho mais rápido, mas por rotas que levam a mais surpresas, visuais, encontros, etc. O mirar pode ser pensado além 
do mirante infinito, buscando possibilidades de um mirante de recortes da paisagem? Esses foram alguns dos questionamentos que influenciaram diretamente na direção do partido do projeto.

O primeiro estudo algorítmico para a Praça da Bandeira irá se fundamentar nessas proposições e tentar reproduzir planos inclinados dinâmicos, definidos através de vetores

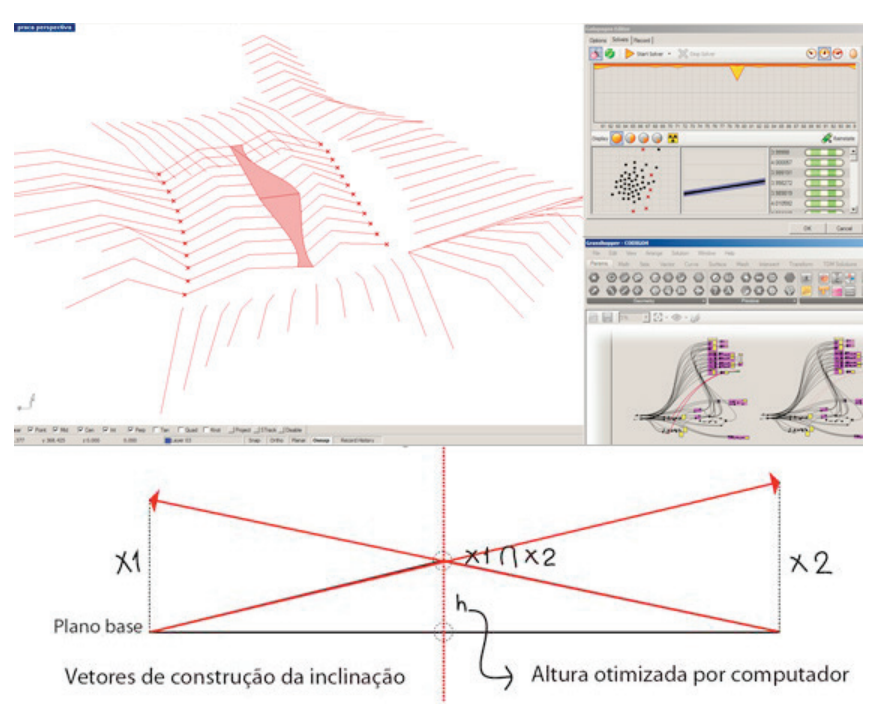

Figura 1

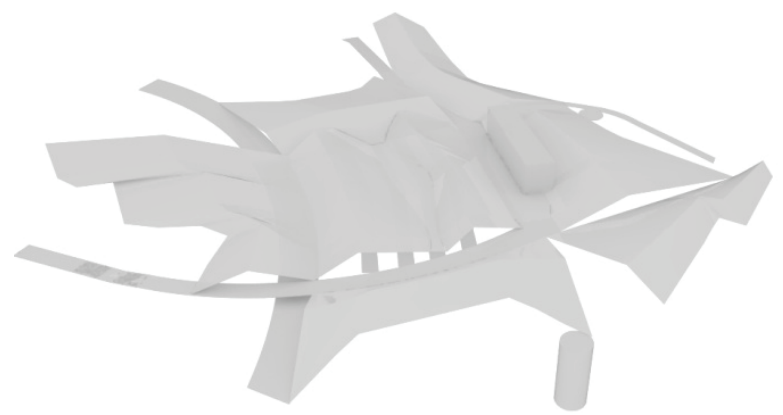

Figura 2

controlados por algoritmos genéticos. Esses planos criam uma malha enrugada que proporciona uma maior rigidez geométrica, criando uma dinâmica para os caminhos e permitindo uma melhor entrada de luz e saída dos gases dos veículos.

\section{Ensaio 2}

A segunda parte do processo buscou uma nova interpretação possível da Praça como elemento de conexão de fluxos e ponto de conjunção de atividades. A síntese se fez por um plano que conecta o Vale entre as cotas mais elevadas e se desdobra buscando ramos de conexão estratégicos que atendem ao fluxo de pedestres da região.

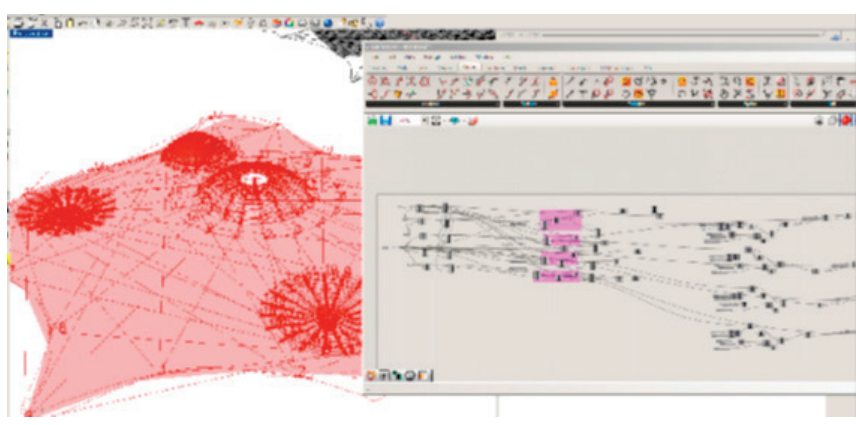

Figura 3

Os fluxos da Praça são organizados por círculos que se transformam em "morrotes" através de uma deformação topológica, que estabelecem hierarquias espaciais e visuais, tornando o espaço mais dinâmico e também trazendo mais surpresas visuais ao transeunte.

A circulação de veículos do Terminal é mantida, sendo que a parte administrativa é repensada tanto na disposição espacial quanto nas atividades envolvidas com a mesma. As áreas escolhidas para a intervenção que conformam o entorno, funcionaram como geradoras de fluxos e qualificadoras da região, criando um pano de fundo para a paisagem, conformando e validando-a como elemento de importância na malha da cidade.

\section{Ensaio 3}

O ensaio três buscou o desenvolvimento das ideias contidas no segundo ensaio, com um maior aprofundamento das questões para fins de apresentação e discussão.

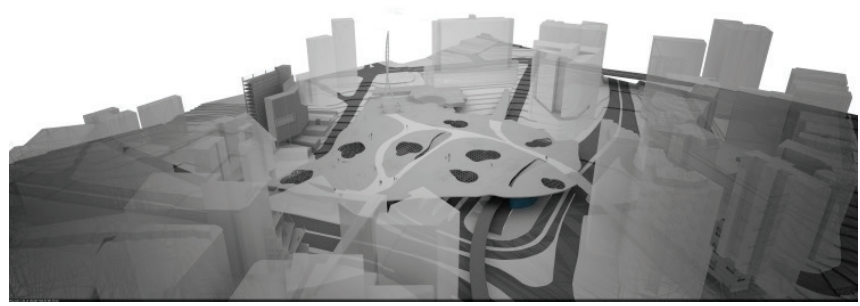

Figura 5

A fim de viabilizar o projeto, alguns eixos de fluxos previamente estabelecidos tiveram que ser abandonados, pois não foi possível formalizar, dentro dos prazos, uma possibilidade formal para atender às normas de acessibilidade vigentes para circulação vertical.No quesito formal não houve muitas mudanças. Mantiveram-se os "morrotes", que se adaptaram à somatória dos novos fluxos que compunham o espaço. Os fluxos mantidos foram: conexão com o metrô através do Largo da Memória, conexão com o Centro Velho através da rua do Ouvidor, conexão com a rua Santo Antônio e, por fim, a conexão com o Paço da Câmara Municipal. 
A cobertura serviria de passagem, praça e conexão com o terminal. O terminal de ônibus nessa etapa teve somente a área construída alterada, sendo mantida a circulação atual dos ônibus.

Os objetos que compuseram a área administrativa do terminal se alocaram dentro de perímetros já estabelecidos, e não apresentaram acréscimos de ocupação. Estes objetos eram compostos por 3 níveis e o acesso era feito através do nível mais elevado por uma rampa. O algoritmo desenvolvido nesta etapa é: dada uma superfície amorfa, definida por seções côncavas e convexas, define-se a triangulação da mesma a fim de sempre se obter chapas planas, dentro de dimensões que viabilizem o transporte, respeitem as características de estabilidade e estejam dentro das dimensões das chapas existentes no mercado.

O nível de acesso era composto por oficinas públicas. Descendo um nível encontrávamos lojas e o nível térreo era composto por toda área administrativa que normalmente compõe um terminal de ônibus.

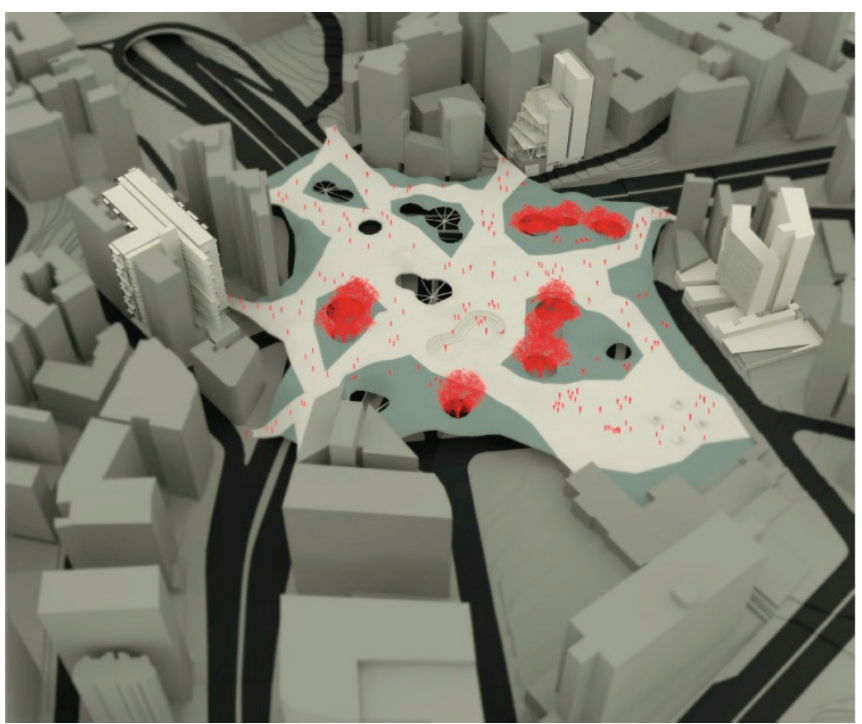

Figura 4

\section{Ensaio 4}

O desenvolvimento do ensaio 4, acreditamos, foi o que obteve o resultado mais enriquecedor dentro de todo o processo. As diretrizes projetuais e a abordagem dos fluxos lindeiros mantiveram-se os mesmos da etapa passada.

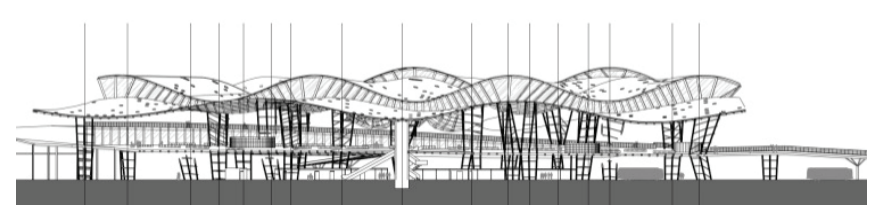

Figura 6

A nova questão desta etapa foi adoção de uma cobertura, que a partir deste momento seria o tema principal do trabalho.
Envolvido pelo tema e pelo impulso de fazer algo realmente interessante, a ideia seria de desenvolver um projeto que fosse quase integralmente algorítmico e em grande parte paramétrico.

Este objetivo de desenvolver algo totalmente algorítmico/paramétrico demonstrou-se na prática um caminho bastante tortuoso, pois no decorrer do processo, conforme o código foi crescendo, o "poder" de processamento dos computadores atuais, tão exaltados em bibliografia específica, vai passo a passo se tornando cada vez mais ineficiente, conforme a quantidade de cálculos exigida cresce quase que exponencialmente, nos levando a pensar que a arquitetura algorítmica de grandes edifícios, ou está a espera da "singularidade" (3), para os arquitetos, ou que estaria reservada a ser desenvolvida apenas por megaescritótios com Workstations de ultima geração. Logo, percebe-se que, por se tratar de fluxo informacional, a questão da velocidade de processamento tornase essencial para se projetar baseando-se nesta maneira de se fazer arquitetura. Além disso, cabe ao arquiteto equalizar o fluxo informacional dentro do maquinário que possui.

Como no mundo contemporâneo, que é marcado pela quantidade de informação disponível, para todos, na questão de um click, na arquitetura algorítmica torna-se essencial que o arquiteto tenha domínio na escolha das informações que possui, de como elas se relacionam e quais são as possibilidades que se pode obter.

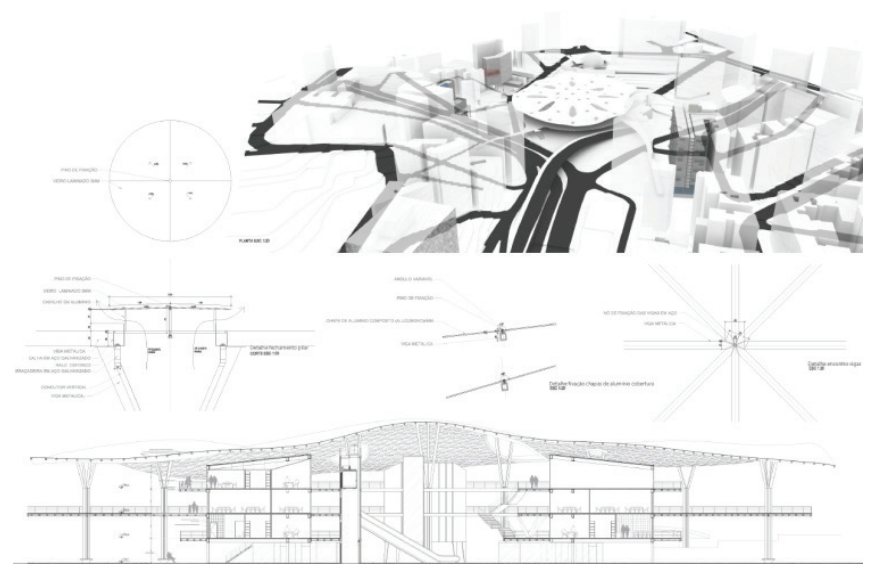

Figura 7

O claro domínio do dataflow torna-se campo do arquiteto que deseja trabalhar em meio essa metodologia.

Um dos erros nessa etapa foi não se ater a quantidade necessária neste quesito e subestimar a complexidade envolvida em um grande bloco de códigos, onde tudo respondia parametricamente. Logo, qualquer modificação feita poderia levar de alguns minutos a horas, o que terminava com a proposta de um projeto paramétrico de possíveis e rápidas alterações no processo, (essa decisão errada acarretou em um grande atraso da documentação final do projeto para esta etapa). Foi tomando a decisão de separar o grande código em pequenos blocos que, de certa 
maneira, interrompia-se o fluxo de informação continua, mas garantia-se o processamento dentro de um tempo admissível.

\section{Ensaio 5}

O ensaio cinco buscou uma experiência mais moderada se comparada ao ensaio quatro.

A vontade de um processo totalmente algorítmico ficou documentada na etapa anterior, e optamos por uma parametrização dos elementos primordiais, respeitando o partido e conceitos adotados e viabilizando o projeto construtivamente, o que resultou em algo mais coerente frente às questões arquitetônicas.

As diretrizes projetuais se mantiveram, e a abordagem dos fluxos lindeiros ganha maior dimensão e profundidade, pois seriam o input externo que daria a forma final à cobertura.

O programa de necessidades ganha uma nova dimensão e se compõe por galeria de arte, praça e terminal urbano. Todos compondo planos que conectam distintos pontos da topografia do entorno, costurando-os em um objeto, um catalisador e dissipador de fluxos, resolvendo em parte um dos problemas da região, referente à mobilidade urbana.

A cobertura, nesta etapa, é o resultado do rebatimento da somatória dos fluxos, contabilizados em PPM (pessoas por minuto), uma estimativa baseada na frequentação atual do terminal com um aumento projetivo de pessoas para daqui a 20 anos. Estes PPM se dividem pelo perímetro de acordo com a hierarquia de importância dos acessos projetados para o terminal.
Os algoritmos utilizados nesta etapa são: o paisagismo do entorno e da praça, o desenvolvimento recursivo da superfície que responde à intensidade de fluxo que passa pela área do projeto, a triangulação desta superfície amorfa a fim de viabilizar a execução e o transporte, a numeração das peças utilizadas, o auditório do Paço da Câmara Municipal, a grelha estrutural de todos os níveis, os pilares, as rampas de acesso e a drenagem das águas pluviais da cobertura. Todos os códigos foram desenvolvidos em pequenos blocos, o que viabilizou o sucesso da parametrização.

Esses ensaios foram realizados tanto de forma purista, explorando-se do inicio ao fim um processo paramétrico, quanto com uma abordagem flexível, desenvolvida a partir de um misto entre design digital e design tradicional.

\section{Considerações Finais}

Sem pretender que uma arquitetura algorítmica possa apontar verdades absolutas dentre os demais métodos de projeto, argumentamos que possa ser uma maneira eficaz de se pensar e fazer arquitetura.

\section{Referencias}

Terzidis, K. (2006). Algorithmic Architecture. Architectural Press Editora.

Bucci, A. (1998). Dissertação de mestrado. Anhangabaú, o Chá e a Metrópole: São Paulo, FAUUSP.

Kurzweil, R. (2005). The singularity is near: When Humans Transcend Biology: Penguin Books Editora. 